\title{
Um estudo da cartilha Víhikaxopovope Yúhoikopea Ûti Vemó'u: Identidade e discurso do povo Terena
}

\section{(A study of the spelling book Víhikaxopovope Yúhoikopea Ûti Vemó'u: Terena people's identity and discourse)}

\author{
Vânia Maria Lescano GUERRA \\ (Universidade Federal de Mato Grosso do Sul/UFMS) ${ }^{1}$ \\ Claudete Cameschi de SOUZA \\ (Universidade Federal de Mato Grosso do Sul/UFMS) $^{2}$
}

\begin{abstract}
Resumo: De uma perspectiva discursivo-desconstrutivista, com base nos estudos de Derrida e Foucault, temos por objetivo problematizar como a produção das identidades dos povos indígenas emerge na escritura de uma cartilha para falantes Terena, publicada em 1972 e usada, até hoje, como suporte prático no trabalho didático-pedagógico, especialmente por indígenas da região de Aquidauana e Miranda (MS). No exame do processo identitário instaurado nos textos da cartilha, analisamos as marcas linguísticas de exclusão presentes nessa escritura. Sustenta, ainda, nossa reflexão, sob a ótica da transdisciplinaridade (CORACINI, 2007), a ideia de transculturação como um processo capaz de gerar uma diversidade de elementos culturais híbridos, resultados da mescla conflituosa ou pacífica de duas ou mais culturas (MIGNOLO, 2003). Nesse contexto discursivo de poder histórico, globalizado, o discurso da cartilha contribui para as relações de saber/poder dos povos indígenas, impondo-lhes "novas identidades", como branco, forçando-os a uma construção identitária considerada fluida e múltipla.
\end{abstract}

Palavras-Chave: Povos indígenas. Material didático. Identidades. Pluralidade cultural.

\begin{abstract}
Starting to a discursive and deconstructive perspective, based on Derrida and Foucault's studies, it has a goal to problematize how indigenous identity emerges in the writing of spelling book for Terena speakers, published in 1972, and used, until the present days, to support didacticpedagogic tasks, mainly by Indians from Aquidauana and Miranda (MS). Through the examination of linguistic marks of exclusion into texts from spelling book, the establishment of identity process was analyzed. Besides, supports this analysis, under the transdisciplinary perspective (CORACINI, 2007), the idea of transculturation as a process able to generate a diversity of hybrid cultural elements, as a result of conflict or pacific blend of two or more cultures (MIGNOLO, 2003). In this discursive context of historical power, globalized, the spelling book's discourse contributes for indigenous people's relations of knowledge/power, laying on them "new identities", as white, enforcing them to a making identity considered flow and multiple.
\end{abstract}

Keywords: Indigenous people. Didactic Material. Identities. Cultural plurality

\section{PALAVRAS INICIAIS}

Aqueles momentos ou processos que são produzidos na articulação de diferenças culturais.

\footnotetext{
${ }^{1}$ Doutora em Linguística e Língua Portuguesa pela UNESP (Araraquara), docente da Universidade Federal de Mato Grosso do Sul - UFMS e pesquisadora do Conselho Nacional de Desenvolvimento Científico e Tecnológico - CNPq. E-mail: vguerra1@terra.com.br

2 Doutora em Educação pela UNESP (Marília); docente da Universidade Federal de Mato Grosso do Sul UFMS. Autora e gestora da Licenciatura Intercultural Indígena "Povos do Pantanal" - UFMS/CPAQ. E-mail: cameschi@terra.com
}

(C) Revista Moara, n.42, jul.-dez. 2014, Estudos Linguísticos. ISSN 2358-0658 (Impresso).

Programa de Pós-Graduação em Letras / Universidade Federal do Pará. Todos os direitos reservados. 
Esses "entre-lugares" fornecem o terreno para a elaboração de estratégias de subjetivação - singular ou coletiva - que dão início a novos signos de identidade e postos inovadores de colaboração e contestação, no ato de definir a própria ideia de sociedade. (BHABHA, 2003, p.20)

As temáticas "indígenas" e "exclusão" não são recentes, de modo que a elaboração deste trabalho pode contar com obras que abordam esses temas de diferentes perspectivas. Guerra (2010), em seus estudos de pós-doutorado na Universidade Estadual de Campinas (UNICAMP), pesquisou sobre a manifestação da produção da identidade do indígena sulmato-grossense em discursos oficiais, materializados no "Estatuto do Índio" e em documentos da "I Conferência Regional dos Povos Indígenas de Mato Grosso do Sul", ocorrida em Dourados, em 2005. Contrariando a "armadilha paternalista da vitimização", Guerra (2010, p. 86) chega à conclusão de que alguns povos indígenas realmente se percebem como membros atuantes de sua nação e que, se suas condições de vida se mantêm de forma favorável, não seria em virtude de benefícios por parte de outros, mas sim como resultado de sua própria atuação na sociedade em que vivem.

A visão tradicional do índio como alguém vulnerável decorre de fatores históricos. Cunha (1992), com a colaboração de outros estudiosos de Antropologia, Arqueologia e História, compilou estudos sobre a História dos Índios no Brasil, concluindo que, após o "descobrimento" do País pelos navegadores portugueses, deu-se também a dissolução da identidade indígena. Os índios já não eram mais considerados os senhores das terras "descobertas", mas sim uma possibilidade de auxílio na exploração dessa nova conquista e, posteriormente, uma "mão de obra barata", de que resultou, marcada na História e no imaginário social, uma suposta posição inferior do índio, que permanece até a atualidade.

Também focalizando o cultural e o identitário dos povos indígenas, Cardoso de Oliveira (1976) estudou "processos de assimilação de culturas e aculturação" que envolvem os índios, caracterizando a assimilação como um "processo" em que o índio terena perde sua "peculiaridade cultural" e sua "identificação étnica anterior" (CARDOSO DE OLIVEIRA, 1976, p. 103).

Articulando os fatores culturais dos povos indígenas ao viés discursivo, Limberti (2009) propõe uma "reflexão teórica sobre subjetividade e identidade", com base em relatos da oralidade dos índios kaiowá da Reserva de Dourados - MS. A pesquisadora traz à tona alguns elementos do "código de representação do indígena", pelo qual chega à compreensão e solução dos problemas característicos dos povos com "especificidades etnoantropológicas" singulares, como os kaiowá. E neste estudo sobre o povo terena, podemos "dialogar" com a obra de Limberti à medida que a busca pela representação do índio guarani propagada pela mídia é uma forma de chegar à raiz dos problemas que afetam a sobrevivência física e cultural desse povo na atualidade.

Posto isso, a partir de uma perspectiva discursivo-desconstrutivista, este trabalho ${ }^{3}$ problematiza como a produção das identidades dos povos indígenas emerge na escritura de uma cartilha para falantes terena, publicada em 1972 e usada, até hoje, como suporte para o trabalho didático-pedagógico dos professores indígenas, sobretudo os da região de Aquidauana e Miranda (MS). Vibikaxovope yúhoikopea ûti vemô'u, ou "Cartilha para aprender a ler em nossa língua", foi elaborada e compilada por Elizabeth Ekdahl e Nancy Butler para ser utilizada no Programa Interinstitucional de Ensino Bilíngue - Terena. Os desenhos que integram o material foram feitos por Pedro Luiz Gomes Lulu, da região do Ipegue.

\footnotetext{
${ }^{3}$ Parte integrante da pesquisa, financiada pelo $\mathrm{CNPq}$, intitulada "O processo identitário do indígena de Mato Grosso do Sul: análise documental e midiática da luta pela terra” (Processo: 471597/2010-4), sob a a coordenação de Vânia Maria Lescano Guerra.
} 
No início da cartilha, as autoras explicam que tal trabalho foi decorrente de estudos fonológicos e gramaticais realizados por elas, na condição de membros do Summer Institute of Linguistics, de acordo com a Portaria 75/N/FUNAI de 06/07/1972. Esclarecem, portanto, que a cartilha é resultado das pesquisas realizadas por ocasião do convênio "Ministério do Interior - Fundação Nacional do Índio - Summer Institute of Lingustics" e do convênio "Museu Nacional - Summer Institute of Lingustics", sendo impressa pela Sociedade Internacional de Linguística (SIL) em Cuiabá (MT). O "Índice" desse material didático traz 14 Lições, articuladas em um total de 70 páginas, integrando uma coletânea de três volumes, que vão apresentando, gradativamente, aspectos gramaticais e fonológicos da língua Terena ${ }^{4}$.

Temos por meta examinar o processo identitário instaurado nos textos desse material didático, analisando as marcas linguísticas de exclusão/inclusão presentes nessa escritura. Ao analisarmos as possibilidades e limites da leitura, entendemos que a interpretação é sempre um texto por fazer, ao mesmo tempo em que esse texto se quer acabado para ser desfeito no tempo da leitura posterior. (BARTHES, 1980). Nesse jogo e troca de papéis, ocorre não só um descentramento do(s) sujeito(s) e do próprio texto, como uma "briga" pelo poder da autoridade textual. Esta, por sua vez, fica relegada: perdeu de vez seu lugar de "mestre" e circula agora ao longe da margem, quer do texto quer da leitura. A assinatura, aí, acontece sempre do lado do destinatário, conforme postula Derrida (1995). Porque texto, escrita e leitura são lugares limítrofes e, por isso mesmo, para sempre dessituados.

Buscamos, neste trabalho ${ }^{5}$, desvelar a construção dos efeitos de sentido do discurso da cartilha Terena e, assim, buscar os efeitos de verdade que emergem da opacidade do discurso travestida pelas aparentes neutralidade e transparência, para, desse modo, mostrar a configuração discursiva da representação identitária que a escritura traz dos povos indígenas, em face da exclusão dessa cultura.

Nesse sentido, cabe-nos recorrer a Derrida (2003), que, não por acaso, vai falar em hostipitalidade (hospitalidade + hostilidade). A condição de fronteira na qual se situa o lócus cultural aqui denominado de fronteira sem lei (Mato Grosso do Sul/Paraguai/Bolívia) condena o lugar a se abrir, ou estar eternamente aberto para uma hospitalidade incondicional, ou, talvez, uma hostipitalidade incondicional. Segundo Derrida (2003, p. 41), a hospitalidade incondicional, pura ou de visita, "consiste em deixar advir o visitante, o que chega inesperadamente sem the pedir contas, sem lhe exigir o passaporte". Essa atmosfera de um visitante sem convite e sem documento ilustra o corredor de passagens e de transeuntes que migram de um lado para o outro da aparente fronteira sem lei do Oeste brasileiro. (NOLASCO, 2009).

Já a análise transdisciplinar de excertos da Cartilha que constitui a segunda parte deste trabalho, fundamenta-se, em primeiro plano, na identificação das formas de poder que regem o discurso sobre os povos indígenas. Para tanto, fundamentamo-nos na obra de Foucault (1990), que, por meio de seu "Método", estudou a função do poder na sociedade com base nos discursos sobre o sexo e a sexualidade. É pertinente, no entanto, que se examine aqui o poder relacionado à escrita e à exclusão.

Para Foucault (1990), discurso e poder se inter-relacionam, de modo que as relações de poder permeiam a produção do discurso, e o poder surge como questão metodológica. $\mathrm{O}$ poder não se localiza em instituições como o Estado; não é algo que um indivíduo cede ao soberano; o poder é, antes, uma relação de forças e, como tal, está em todas as partes, ou

\footnotetext{
${ }^{4}$ Essas autoras participaram diretamente no Projeto Raízes do Saber, desenvolvido em Aquidauana, numa proposta de inserção das disciplinas Língua Terena e Arte e Cultura Terena (1999) nas escolas das comunidades indígenas Terena da região. O projeto traz uma proposta de metodologia que parte da modalidade oral para a modalidade escrita da língua, por meio de temas cotidianos da comunidade, ainda em uso pelos professores da rede municipal.

${ }^{5}$ Esta pesquisa faz parte do Grupo Vozes (In)fames registrado no CNPq e coordenado pela Profa. Maria José Rodrigues Faria Coracini (IEL-UNICAMP).
} 
seja, o poder atravessa todas as relações pessoais e sociais, de modo que uma pessoa não pode ser considerada fora dessas relações de poder.

Foucault (2005) chama de arquivo a soma de todos os discursos possíveis, sem estabelecer nenhuma hierarquia de valores, apenas buscando as regularidades do discurso. É sobre esse arquivo que a arqueologia deve incidir. O método arqueológico investiga a natureza do poder na sociedade a partir dos discursos produzidos na sociedade numa dada época. Para o filósofo, interessam os discursos sobre a psiquiatria, a medicina e o direito, saberes cuja natureza, rejeitando qualquer tentativa de unificação da memória coletiva, da linearidade histórica, busca na descontinuidade e na dispersão os fundamentos de sua pesquisa.

Além de identificar (re)apresentações dos indígenas “(re)construídas” na discursividade da cartilha para falantes Terena, também se pretende que este trabalho contribua para que novas pesquisas sejam realizadas nesse campo. Pesquisas que focalizem o choque cultural de uma inclusão supostamente benemerente do índio na sociedade - a qual frequentemente cai na "armadilha paternalista da vitimização" ao instituir programas sociais de inclusão, supondo sua incapacidade -, mas que o expõe a representações que distorcem sua imagem. (GUERRA, 2010). Assim, a propalada inclusão o tornaria não um igual entre seus pares na sociedade, mas um estranho sempre visto de forma equivocada e ultrapassada, baseada em (re)apresentações (re)construídas por discursos diversos.

$\mathrm{O}$ olhar discursivo-desconstrutivista ligado às noções de discurso e identidade e o foco nas questões culturais surgem, pois, como princípios teórico-metodológicos direcionadores do trajeto desta pesquisa, que dialogam entre si de forma instigante e produtiva. Outra perspectiva metodológica relevante diz respeito à genealogia de Foucault, em que a problematização das relações de poder que se instauram nos interdiscursos, resultando nas possíveis representações, denunciam a existência de um discurso estereotipado que rotula e nega o jogo da diferença, o hibridismo, a alteridade que está na base da identidade.

Passemos, então, a estudar, sob a ótica da transdisciplinaridade (CORACINI, 2007), as teorias discursivas e culturais que sustentam nossa reflexão, no que tange ao processo identitário dos indígenas. A ideia de transculturação como um processo capaz de gerar uma diversidade de elementos culturais híbridos, resultados da mescla conflituosa ou pacífica de duas ou mais culturas (MIGNOLO, 2003), também será mobilizada neste texto a partir da análise de um processo transcultural de apropriação e reapropriação que transforma e/ou multiplica, mina, destrói e reconstrói as fronteiras e os espaços entre elas.

Nesse contexto discursivo de poder social, histórico, globalizado, visamos comprovar (ou refutar) a hipótese de que o discurso da cartilha, na condição de material didático, contribui para as relações de saber/poder dos povos indígenas, impondo-lhe "novas identidades", como brancos, forçando-os a uma construção identitária considerada fluida e múltipla.

\title{
2 AS PRÁTICAS IDENTITÁRIAS E O JOGO DA DIFERENÇA
}

\author{
A colonialidade é parte constitutiva a \\ modernidade, é seu lado sombrio, oculto e \\ silenciado. [...] Assim, a modernidade e a \\ colonialidade do poder são duas faces de uma \\ mesma moeda. (MIGNOLO, 2003, p.75-76)
}

A palavra "poder" está cercada de significações negativas, que remetem a dominação e subjugação (FOUCAULT, 1990, p. 92), entretanto o conceito de poder é bem mais 
abrangente do que se julga: ele opera e organiza-se em diversos setores da sociedade, personificando-se nos aparelhos do Estado, na formulação das leis e nas hegemonias sociais. (FOUCAULT, 1990, p. 93). Personificado em vários lugares, não se pode afirmar que o poder deva, a rigor, estabelecer condições de subserviência, embora por vezes seja essa a representação que é formada a partir de sua existência.

Analisamos o discurso - via texto da cartilha terena - pelo qual o processo de interação verbal se concretiza, considerando que o discurso permite, ao(s) sujeito(s), marcar(em) presença histórica e social no contexto da língua/linguagem. Acima de tudo, no e pelo discurso, é possível vermos nossa experiência simbólica e de mundo, abordando não somente a maneira pela qual os indivíduos se tornam sujeitos de governo e objetos de conhecimento, mas também a maneira pela qual se acaba por exigir que os sujeitos produzam um discurso sobre os outros e/ou sobre si mesmos - sobre existência, sobre trabalho, sobre afetos -, tornando as experiências e cotidiano cercados de múltiplos saberes perceptíveis na relação de um "biopoder". (FOUCAULT, 2010, p. 78).

Enfocar a cultura no âmbito do poder e do conflito pode ser um meio para perceber a pluralidade e a diferença dos povos. Daí o híbrido não representar simplesmente a combinação tradutória de dois originais - um terceiro elemento que resolveria a tensão entre duas culturas. Híbrido aqui é um processo agonístico e antagonístico em estado constante de negociação inconclusiva, sem trégua, sem assimilação nem incorporação.

Nesse sentido, a crítica feita por Derrida (1995) ao modo estruturalista de interpretação reside no fato de aí se ter reverenciado o significado, em detrimento da própria força do significante; de se ter valorizado a profundidade em prejuízo da superfície; de se terem privilegiado apenas as oposições; de se ter descartado, portanto, a diferença - do signo que não encontrava seu lugar nos paradigmas semânticos exclusivamente opositivos e binários; de não ter permitido falar o próprio significante; enfim, de não ter deixado aflorar a interpretação indecidível - a interpretação da interpretação.

Essa interpretação fundamentada na différance é a mola propulsora desse pharmakon, que é a escrita. A metáfora do pharmakon, com que trabalha Derrida, em A farmácia de Platão (2005), permite a ilustração da atividade interpretativa que não se decide por um único significado do signo, uma vez que, contrariamente, impulsiona a força do significante. Remédio e veneno, o pharmakon é essa différance, esse instante em que os diferentes significados se encontram presentes.

Segundo Derrida (2005), a interpretação não apaga nenhum dos significados; pelo contrário, permite que as forças do remédio e do veneno, do bem e do mal, do claro e do escuro aflorem. Enfim, de todas as oposições, de todas as distinções, de todas as différences passíveis de verificação, tendo em mente o princípio de que a escrita é escritura, de que a escrita é différance. Logo, na interpretação pensada segundo as bases do desconstrutivismo derridiano, o que se tem a fazer é acionar a indecidibilidade, permitir a irrupção da polissemia, fazer emergirem os significados, dar voz à alteridade, disseminar os significantes, agenciar o jogo desses significantes, privilegiar a mobilidade característica da estruturalidade da estrutura, ou seja, mobilizar a força do texto.

A esse respeito, Foucault (2005) traz um posicionamento singular quando afirma que a interpretação do que nos cerca é relativa e nossa compreensão é parcial, oferecida pelas versões, pelos ensaios, que nos oferecem visões parciais da complexa rede textual que nos envolve. Para ele, subjacente ao processo interpretativo que quisesse ir em direção à profundidade, restaria a falsa premissa de que o símbolo conduziria à coisa em si, como se o símbolo repousasse numa origem que lhe pertencesse, ou se colasse à coisa que apenas simboliza.

$\mathrm{Na}$ esteira de Derrida, Coracini e Foucault, podemos dizer que o ato de ler possui suas implicações em múltiplas estâncias do saber, de que derivam relações tensionais. É na tensão que se formam os sentidos. Um dos grandes méritos dessa abordagem de leitura é propiciar, ao professor em exercício e aos profissionais interessados na constituição 
heterogênea da linguagem, reflexões que implicam, em última análise, indagar, de um lado, sobre a natureza humana e, de outro, sobre a formação do sujeito contemporâneo. Como afirma Pêcheux (1988, p. 294), "intervir filosoficamente obriga a tomar partido: eu tomo partido pelo fogo de um trabalho crítico".

Imbricada nessas vozes, não podemos deixar de ouvir a voz do colonizado, daquele que, para sobreviver, precisa aceitar o lugar que lhe é "concedido", ainda que esse lugar o transforme em objeto de exclusão para o outro; afinal, esse também é um modo de garantir sua existência. Ou então o estrangeiro, o índio, permanece no imaginário do brasileiro, como o indesejável, aquele que se gostaria de esquecer, de banir, porque perturba, exibe a própria fragilidade indesejada, mas que está aí, no inconsciente, na memória. Reminiscências de um passado esquecido, mas que se faz presente o tempo todo no inconsciente, que pode manifestar-se em "ressentimento" ou numa certa implicância que o leva a ressaltar os defeitos do outro, suas falhas e sofrimentos, na busca de um consolo para o seu próprio sentimento de inferioridade; e esse ressentimento ou essa implicância o fazem viver, dar sentido à sua existência e lhe imprimem um sentimento de identidade.

Entender as práticas identitárias a partir do jogo de representações é entender quais os discursos que constituem e conferem existência histórica ao sujeito. E ao falar em diversidade, em diferença, temos que considerar que as culturas são diversas e cada uma tem a sua lógica, sua organização social e seus valores, razão por que devemos tentar compreender suas especificidades não necessariamente estabelecendo uma troca; a noção de diferença compreende as relações entre as diversas culturas permeadas por jogos de poder. Para Eckert-Hoff (2008, p. 43), "o sujeito se constitui, pela dispersão e pela multiplicidade de discursos e, ao enunciar, o faz ocupando várias posições, que marcam a sua heterogeneidade". Assim, estamos entendendo a formação ligada a um processo multifacetado e plural, cujas vozes, práticas e saberes articulados encontram-se acumulados em todo o percurso histórico e social do sujeito. Vale dizer que tal formação se desenvolve pelos deslocamentos, num constante movimento de identificações, que constitui a subjetividade heterogênea do discurso e do sujeito, e abarca sua formação.

Bhabha (1998, p. 41) pensa a nação a partir de suas margens: as vivências das minorias, os conflitos sociais, o arcaico chocando-se com o moderno, a exclusão. A escrita jamais depara com infinitas intervenções que transpassam a vivência. Inclusão e exclusão não são polos opostos; elas compõem a dinâmica da sociedade globalizada, onde a fluidez das margens não permite as demarcações rígidas, produzindo o entre-lugar, no qual podemos pensar em inclusão-excludente ou exclusão-includente.

Por fim, importa acrescentar que estudar, analisar e problematizar o discurso requer, entre outras coisas, percorrer o caminho trilhado pelas condições de produção (CPs), já que, da perspectiva discursiva, a língua deve ser estudada em suas CPs, pois os mecanismos que a compõem são histórico-sociais.

\section{MARCAS DA EX/INCLUSÃO DO INDÍGENA E DA PLURALIDADE CULTURAL NO DISCURSO DA CARTILHA}

Nosso interesse neste estudo é advindo de pesquisas anteriores (GUERRA, 2010; 2012), em que constatamos uma representação genérica também presente em documentos oficiais e materiais didáticos, o que demonstra a relevância desta discussão, que tem como objeto de análise um material impresso utilizado no universo escolar, e a partir do qual alunos indígenas recebem informações sobre a alteridade.

Segundo Novaes (1999), a partir da chegada dos europeus à América, uma considerável gama de representações sobre os povos aqui encontrados começou a ser 
construída, inicialmente por um olhar de estranhamento perante a nova terra e seus habitantes, relatado por vários cronistas e viajantes desse período.

Diante disso, a partir século XVI, duas imagens, carregadas de elementos que diferenciavam esses habitantes dos cristãos europeus, alicerçaram essas representações: o bom e o man selvagem. A leitura dessa diferença foi feita por muitos pensadores a partir da ideia de falta, isto é, do que estava "ausente" no outro.

Já no século XIX, foi mobilizada, por diversas correntes de pensamento, a questão da extinção dos povos indígenas, sobretudo advinda de pressupostos evolucionistas: os povos indígenas passaram a ser vistos como primitivos, sendo os europeus, os povos então "civilizados", a referência nessa escala evolutiva. Muitos estudiosos que, de uma perspectiva "utilitária e funcionalista", descreveram os índios a partir da atuação dos europeus, não hesitaram em impor as suas visões de mundo e, nas suas representações, não havia lugar para o diferente. Inexistia um trabalho de interpretação a exigir reflexão sobre o que era visto. (NOVAES, 1999, p. 10). Havia, dessa forma, uma apropriação de determinados valores e concepções e a consequente construção imaginária sobre a alteridade. Nessas construções, os povos indígenas são quase sempre estudados no passado, aparecem à sombra do colonizador, numa representação que reforça a tendência etnocêntrica de grande parte da historiografia em curso.

Desde então, esses povos têm tido uma participação pouco expressiva em nossa historiografia e no cotidiano escolar, sendo geralmente estudados como coadjuvantes, vítimas indefesas, dominados, aldeados e "assimilados", sem autonomia. Segundo Moreira (2000), essas interpretações construíram uma imagem estática dos índios e tendem a afastálos da história, e, o que é mais preocupante, essa representação está posta em muitos materiais didáticos, que, no âmbito escolar, são influentes instrumentos no processo de ensino-aprendizagem.

Apesar da produção e acumulação de um conhecimento considerável sobre as sociedades indígenas, esse conhecimento ainda está muito preso aos espaços das universidades. Chegamos ao século XXI com uma profusão de imagens sobre os índios. É a visão homogeneizadora do índio, perpassada, nas escolas de todo o Brasil, na comemoração do "Dia do Îndio", quando as crianças são pintadas pelas professoras e enfeitadas com penas para representá-los. É a imagem do índio condenado pela "civilização" à extinção inexorável, índio esse que nos deixou herança cultural (como se ele já tivesse desaparecido!). São índios vistos como seres inferiores, ingênuos, vítimas, dignos de nossa compaixão. (GUERRA, 2010). De modo geral, no Brasil, a temática indígena ainda é relegada a um segundo plano, os estudos historiográficos são poucos e os materiais didáticos, muitas vezes, perpetuam uma imagem estereotipada desses povos.

Compete à crítica que opta pela visada descolonial exumar essas memórias e histórias esquecidas e reinseri-las no debate contemporâneo, respeitando seus lugares e corpos nos quais elas vivem, sem querer tirá-las de sua condição de exterioridade e querer analisá-las à luz da razão universal (pensamento ocidental). Segundo Walter Mignolo (2003), o projeto universal/colonial homogeneizou as diferenças culturais locais, interiorizando as exterioridades. Mais uma vez, a história velada que entrevemos no sinal da boca cerrada e dos olhos vazados dos indígenas sinaliza o processo de desmontagem e, por conseguinte, de desaprendizagem da crítica de razão pós-subalterna, sobretudo porque a escolha da produção cultural e dos sujeitos indígenas já vem inscrita em seus corpos como condição de subalternidade. Spivak (2003, p. 12) define "subalterno" como pertencente "às camadas mais baixas da sociedade constituídas pelos modos específicos de exclusão dos mercados, da representação política e legal, e da possibilidade de se tornarem membros plenos no estrato social dominante". $\mathrm{Na}$ esteira do pensamento de Spivak, afirmamos que é da natureza do subalterno deslizar-se, distanciar-se de toda representação, mesmo daquele tipo de representação que os estudos subalternos insistem atribuir-lhe. 


\title{
4 DO MOVIMENTO ANALÍTICO E DA CONSTRUÇÃO IDENTITÁRIA DO INDÍGENA TERENA
}

[...] o homem, desde antes do seu nascimento e para-além da morte, está preso a cadeia simbólica [...] é em seu próprio ser [...] como um todo, só que a maneira de um peão, no jogo do significante, e isso, desde antes que as regras do jogo lhe sejam transmitidas [...] essa exterioridade do simbólico em relação ao homem é a noção mesma do inconsciente (LACAN, 1998, p. 471).

Para articular o processo analítico dos textos da cartilha terena (CT), optamos por trabalhar com dois excertos, que são enumerados na mesma ordem do seu aparecimento na cartilha. É pertinente observar que, mesmo escrevendo na década de 1980, data da terceira reimpressão da cartilha, período em que as discussões teóricas sobre a temática já haviam mudado bastante, Bete Ekdahl e Nancy Butler cristalizam visões tradicionais. O contraditório é que, em CT 1, as autoras parecem querer destacar a importância de se discutir a diversidade cultural, bem como os riscos das generalizações, mas apresentam uma visão genérica. Quando falam em respeitar os mais velhos, por exemplo, não discutem que é o branco que não tem a cultura de respeitar seus anciões; ao discutirem que qualquer pessoa deve ser respeitada, não explicitam que alguns grupos não são respeitados.

\begin{abstract}
CT 1 (p.15 lição 3)
Konokoâti téyea ûti ne yékoteno xâne

Ákone áxuna mûyo ne yékoteno xâe itea kónokea téyeokono. Énomone katarákovi vitukóvoiko kalivôno. Utíne konokôa. Kátarakopea koêku yékotixeane. Koêkuti xâne, koati motokeâti téyeokono, kuteâti yékoteno, úsotine xâne, koánemaka ne kalivôno. Yoko kónokinoke téyeokoko ne xâne maka aúnatine koêku ûti. Koane énomone itukóvoxo koati ponóvoti kixovókuti.
\end{abstract}

Temos que respeitar as pessoas mais velhas ${ }^{6}$

Os anciões não têm mais a força física, mas é preciso que seja respeitado [sic]. Eles nos sustentaram quando crianças. Agora nós temos que cuidar, pois estão velhos. Qualquer pessoa tem que ser respeitada, como os anciões, as pessoas de idade, e também as crianças. É importante respeitar um ao outro para ficarmos bem. Essa é a coisa mais certa.

Desse modo, o desejo de completude identitária por CT 1 é saciado pelo poder de conhecer o outro/conhecimentos universais a partir de sua própria língua, motivo que o leva a acreditar na pró-vitalização da Língua Terena, conforme os dizeres dos vários excertos mobilizados pela cartilha em questão. O sentir-se em casa com a língua, conforme Derrida (2001), possibilita ao indígena conhecer outros saberes, porque, para ele, a língua proporciona mecanismos armazenados interiormente, que são ativados quando necessário. Nessa perspectiva, é pertinente incluirmos, nessa discussão, os fundamentos do discurso, na conjuntura do interdiscurso, materializado no intradiscurso por CT 1, recategorizando "velhos", no excerto apresentado, por meio de nomes, pronomes ou lexias relativos aos processos discursivos: anciöes, eles, as pessoas de idade, o outro, que têm como referente "as pessoas mais velhas". Como são analisados no discurso (porque remetem a suposições e hipóteses discutidas no/pelo discurso), assinalamos que tais processos de recategorização de

\footnotetext{
6 Tradução do Terena para o Português de Aronaldo Júlio, Professor Terena da Terra Indígena de Cachoeirinha e acadêmico da Licenciatura Intercultural Indígena "Povos do Pantanal" — UFMS/Campus de Aquidauana.
} 
referentes voltam-se para uma seleção lexical, em que as fontes somente podem ser observadas no discurso.

Podemos depreender, a partir das escolhas lexicais propostas por CT 1, que os efeitos de sentido estreitam-se para a complexidade e o conflito interior vividos pelo sujeito, pois, nas recategorizações articuladas por ele para se referir à problemática do respeito aos idosos entre os indígenas (e brancos), a presença de formações discursivas denuncia um discurso tenso, em "que o sujeito é sempre constituído por seus duplos: tudo é nãocoincidência entre a pessoa e seu nome, entre o eu e o sujeito, entre a língua e sua cultura". (ECKERT-HOFF, 2008, p. 66).

São as relações de poder, que se fazem instaurar em determinados momentos da história, a partir dos acontecimentos, que determinam as possíveis (re)ações dos sujeitos. CT 1, como sujeito do século XXI, representa o indivíduo que busca sobreviver (entendamos sobreviver como um ato amplo em que se conjugam vida e cultura) em meio às identidades fragmentadas, concebendo o outro, embora estranho, como constituinte de sua identidade, indivíduo definido por Eckert-Hoff (2008, p. 40) como "um sujeito camaleônico", que, como camaleão, "muda constantemente de forma e de cor. Nessa metamorfose, ele não deixa de ser um para ser outro, pois um está imbricado no outro, é sempre o mesmo no diferente e o diferente no mesmo". A metamorfose dos sujeitos, num contexto de minoria linguística, representada pela escolha da proficiência na língua majoritária, traz a representação da língua, no caso, a Terena, como mecanismo de controle; sujeitos compostos, conforme Bhabha (1998).

É importante também sublinhar que estamos tratando de um sujeito essencialmente histórico, portanto ideologicamente constituído, cuja fala é um recorte das representações de um tempo histórico e de um espaço social. Ao afirmarmos que o discurso do sujeito se constrói em relação ao discurso do outro, devemos entender que esse outro não é apenas o interlocutor para quem o locutor planeja e ajusta a sua fala. Nele estão envolvidos outros discursos historicamente já constituídos e que emergem na sua fala, ou seja, é a noção de interdiscurso que deve ser considerada, pois "o discurso é um produto de interdiscursos". (AUTHIER-RÉVUZ, 1990, p. 26). Vale observar que não se discute o contexto em que essa cartilha foi escrita, muito menos os interesses que perpassavam as relações de poder. Assim, a visão de cordialidade que é passada no texto reforça a representação dos índios como criaturas puras e dóceis; imagem presente desde o século XVI e que permanece no universo escolar. Mais uma vez, não se discute a importância desses objetos para essas sociedades que não os possuíam.

Quanto ao desrespeito mobilizado no excerto, também aqui se constata a eminência de um outro equívoco. Essas noções foram difundidas por ocasião de conflitos e guerrilhas havidas entre os brancos e indígenas, quando da conquista e exploração da terra brasileira. Os europeus, defrontando-se com os modos plurais de organização social indígena e verificando que estes não se constituíam à sua imagem, reagiram violenta e etnocentricamente. Por não obterem êxito no intento de escravização indígena, impulsionaram a criação de um imaginário desqualificado para atribuir a eles. Portanto, permanecer com visões parciais como as mencionadas é não poder reconhecer a marca da contingência própria das realidades históricas.

Em relação aos povos indígenas, que não representam mais de 700 mil habitantes no país, a maior parte da população brasileira jamais teve contato pessoal com qualquer índio, nem visitou uma aldeia indígena. Como chama atenção Freire (2002), a representação que cada brasileiro tem do índio é prioritariamente aquela que lhe foi transmitida na sala de aula pelo professor, com ajuda do livro didático e dos discursos midiáticos, que tendem a reforçar essa mesma representação. Nesse contexto, as aulas de história são as principais responsáveis pela representação indígena na educação básica, pois muito pouco ou nada se expressa sobre essas culturas nas demais disciplinas. 
Gobbi (2006) afirma, em estudo sobre os livros didáticos, que alguns autores já reconhecem que os livros de História produzidos nos últimos cinco anos têm sido mais generosos ao retratar a "história dos vencidos", mas ainda representam exceções. Na maior parte dos livros de outras disciplinas, ainda se reproduz uma difusão depreciativa dos fatos sociais, tendo o modelo civilizatório ocidental como única verdade. Já Carmagnani (1999) alega que os livros didáticos promovem, por meio de atividades de escrita, discursos que fazem que o próprio aluno desenvolva um modelo interpretativo. Esses modelos podem ser naturais ou de acordo com o professor; outras vezes buscam corresponder à resposta ideal, almejada pelo livro didático. A crença de que dominar regras e modelos vem garantir a elaboração de textos coerentes nem sempre funciona; é preciso permitir que o aluno produza com sentido, criando suas próprias conclusões, possibilitando a criatividade espontânea do leitor/escritor aprendiz.

No caso de CT 1, a escrita da cartilha indígena mobiliza uma representação do branco ligada ao mal, ao desrespeito, à intolerância aos idosos. No contraponto, o fio discursivo de CT 1 traz como imagem positiva o fato de que muitos indígenas respeitam seus antepassados, o que vem conferir ao índio uma mobilidade e um lugar privilegiado na sociedade local. $\mathrm{O}$ novo como ideal do eu transporta o sujeito a outra posição subjetiva que, inevitavelmente, carrega o antigo. $\mathrm{Na}$ perspectiva da completude, o sujeito enuncia "Agora nós temos que cuidar, pois estão velhos"; um modo de fazer em que o novo, não explicitado, está no processo de significação em relação à "falta de". Daí o desejo, "cujo preenchimento total é sempre adiado, em decorrência dessa idealização do novo estar no imaginário do sujeito logocêntrico, centrado, que busca o ideal, a perfeição, a completude, 'esquecendo-se' de que o anterior o constitui, inevitavelmente'. (ECKERT-HOFF, 2008, p. 86).

A marca linguística "agora" é, para Neves (2000, p. 235), advérbio periférico (funciona como satélite do núcleo) no discurso porque incide sobre todo o enunciado; refere-se ao momento da enunciação, numa escala de proximidade temporal, e encontra-se ligado ao enunciador, promovendo uma representatividade do sujeito, alcançada, no caso em análise, com a maturidade indígena. Nesse sentido, há uma relação de forças, conforme propõe Orlandi (2009, p. 39): "podemos dizer que o lugar do qual fala o sujeito é constitutivo do que ele diz". Nesse recorte, confirmamos essa referência, pois, por meio do advérbio temporal "agora" (CT 1), o sujeito "fala como índio", carregando a autoridade que "ser índio permite", ao mesmo tempo em que absorve, inconscientemente, a "ideologia" que circula nas escolas brasileiras: o poder e os interesses de uns sobrepondo-se ao poder e interesses de outros.

Este é um dos efeitos de sentido: o indígena Terena surge como um diferencial nas relações de ensino. De certa forma, a escrita analisada representa o sujeito possuidor de saber/poder, cuja identidade como aluno apresenta-se em processo de construção, confirmando que, "no mundo moderno, o governo de si e dos outros constitui um princípio fundamental de produção de identidade". (GREGOLIN, 2006, p. 50). Como pudemos constatar em CT 1, a identidade do sujeito é marcada por uma "multiplicidade" presente nas relações cotidianas.

O sujeito procura apagar a imagem já cristalizada na memória dos brancos de que todos os povos indígenas possuem apenas uma cultura. Mobiliza-se a ideia de que não há diversidades culturais entre as diversas etnias indígenas de Mato Grosso do Sul. Em especial, no caso de Aquidauana, ressalte-se que, no interior de algumas aldeias, moram povos de duas ou mais etnias (Kinikinau, Terena, Kadiwéu, Guarani, Kaiowá, Xavante, Layano, Bororo, entre outros), em constante interação com os brancos. A relação de não aceitação do diferente, do outro, vem mobilizar um efeito de distanciamento entre a sociedade do branco e a do indígena, já que a tensão desse discurso faz emergir, do silêncio significante, ou seja, do "não dito visto do interior da linguagem", que "não é o nada, não é o vazio sem história" 
(ORLANDI, 2007, p. 23), mas algo que "escorre por entre a trama das falas" (ORLANDI, 2007, p. 32), uma imagem do branco como transgressor e perigoso para a sociedade do entorno: "É importante respeitar um ao outro para ficarmos bem".

A relação de proximidade e distanciamento surge novamente na fala de CT 1, quando o sujeito enuncia que "Temos que respeitar as pessoas mais velhas". A manipulação do enunciador traz à tona um discurso persuasivo, em que a ação é posta em primeiro plano: os brancos surgem como dependentes ou subordinados ao fazer do índio, responsáveis pelas regras morais e éticas da população indígena. $\mathrm{Na}$ busca de elementos argumentativos que garantam ao sujeito a eficácia dessa tese, destacam-se, de um lado, valores positivos indígenas, como união, força, respeito, e, de outro, valores negativos dos brancos, a saber: a desunião, desrespeito e discriminação ao idoso, marcas de exclusão e segregação social.

$\mathrm{O}$ movimento indígena tem-se organizado em associações autônomas a fim de buscar recursos para o desenvolvimento de projetos interculturais dentro de suas aldeias, mas também fora delas. Sabem que ainda não é o suficiente. Cobram do poder público maior empenho para solucionar conflitos e políticas que ajudem a eliminar o preconceito. É nessa possibilidade de qualquer escritura, conforme o pensamento foucaultiano, que a sociedade e, em especial, as instituições (Escola e Estado) controlam a ordem dos discursos, o que tem efeitos sobre a identidade dos jovens indígenas de forma geral. Uma das formas de o sujeito exercer tal poder é constituída na imagem do que é "ser indígena", quando, ao falar de si e do branco (outro), permite diversas maneiras de experimentar a identidade de povo "capacitado", numa posição de resistência e valorização da imagem identitária dos povos indígenas.

Prosseguindo na problematização do discurso, quando CT 1 usa os verbos na primeira pessoa do plural ("temos"), seu discurso mobiliza o efeito de sentido de proximidade entre os índios. Revela a união do povo, a voz de um sujeito coletivo que, pelo seu discurso, traz de volta os já ditos que constroem o imaginário social dos indígenas como sujeitos "Estereotipados como selvagens [...] explorados e perseguidos. [...] uma violência que esconde o preconceito de um país que não assume sua plurietnicidade". (GUERRA, 2010, p. 45).

É fato que a sociedade hegemônica situa os indígenas em lugares de subalternidade, de submissão, de exclusão: é ela que dita as leis e impõe suas condições, como, por exemplo, "só é cidadão brasileiro aquele que aprender a língua portuguesa; é ela que os hospeda, quando, a bem da verdade histórica ainda pouco divulgada nas escolas, os indígenas é que deveriam nos hospedar" (CORACINI, 2011, p. 23); a nós, descendentes de europeus, resultantes de uma mistura étnica e cultural, ao longo dos séculos. Hoje, os poucos índios que restaram não são mais os mesmos, como nós não somos os mesmos, mas "culturas híbridas, complexas, atravessadas pelo desejo de consumo da sociedade globalizada". (CORACINI, 2011, p. 24).

Essas discursividades, que marcam a concepção estereotipada de indígena existente no imaginário do aprendiz e que concorrem para a construção identitária dos sujeitos em estudo, são visíveis também no segundo recorte (CT 2) que analisamos:

CT 2 (p. 68, lição 14)

Pãnana

Enepora Pânana ípuxovoku viyénoxapa, énomone itukóvo koati éxone purútuye. Símoane Koati payásoti hóyeno natína poké'exa ûti, UTI íhaé Brâsiu, yanekôyoke. Koane símoanemaka presidenti-na FUNAI. [...]

Koane ákomaka tôpi kó'iyeovoku uparáti omínoake xanéhiko.[...] Eneponeko kali koyuhópeti omínoake, óvoku kálihunoe exetínati, yútoe neko homoêhou yoko ârunoe ya vemó'uke. [...]

Elóke okóvo neko nâti koêku namúkea neko koyuhópeti, yútoe neko homoêhou yoko ârunoe íhae Mbókoti. 
Yoko inípono êno xâne kaha'âti noíxea neko natina ûti. Êno orekáti yanekôyoke. Koane ápemaka êno oxokéti. Koane ápemaka oye'ékinoati nîka neko nâti íhae pitivóko.

\begin{abstract}
A Aldeia de Bananal
A aldeia de Bananal onde moram nossos patrícios é a aldeia mais conhecida pelos brancos. Já recebeu visita de um dos presidentes do Brasil. Também veio um presidente da FUNAI. [...] As pessoas trouxeram vários tipos de presentes para o Presidente [...]. Naquele livreto estavam escritas algumas histórias que eles tinham escrito na nossa língua [...]. O Presidente ficou contente quando recebeu aquele livreto escrito pelos jovens da aldeia de Cachoeirinha.

Quando o nosso Presidente veio, havia muitos soldados de guarda no lugar onde o avião grande aterrissou [...].

Havia muitas pessoas querendo ver o nosso Presidente. Teve muitas coisas a beber e churrasco também. Vieram mulheres da cidade para fazer almoço para o presidente.
\end{abstract}

Em CT 2, o sujeito inicia sua escrita mobilizando a ideia de que as aldeias indígenas não são conhecidas dos brancos. Seu enunciado deixa emergir uma interdição no dizer ao relatar: "Naquele livreto estavam escritas algumas histórias que eles tinham escrito na nossa língua." Verifica-se, nesse recorte, uma discriminação por origem linguística e geográfica, tendo em vista que há diferença entre os povos indígenas - o que lhe é estranho (cultural e geograficamente) é apresentado na terceira pessoa do singular (o branco e os jovens indígenas de Cachoeirinha). De acordo com professores das escolas com população indígena, a exclusão social está relacionada mais ao local de origem do que às diferenças étnicas entre os indígenas. Em face disso, a escola trabalha com projetos sociais a fim de valorizar o respeito e a solidariedade entre os povos que ali estão, levando os alunos a visitar tais locais, numa preocupação contínua em refletir sobre o problema e envolver a escola na amenização dos conflitos e das diferenças. Verifica-se que, tendo em vista o contato próximo com a aldeia dentro da cidade, os jovens indígenas encontram-se fortemente influenciados pela cultura do entorno, especialmente pelas novas tecnologias da época (datilografado versus desenhado) e pela mídia. Segundo Limberti (2009, p. 26), os adultos também sofrem as consequências desse confronto cultural, no entanto seus valores encontram-se mais arraigados à cultura do índio, apresentando maior resistência ao poder da "aculturação branca".

Podemos observar, ainda, as marcas de subjetividade materializadas no excerto, por meio dos pronomes possessivos nossos, nossa, nosso, que nos permitem depreender os efeitos de sentido decorrentes da inclusão de CT 2 como parte daquilo em que ele acredita: ele é um professor indígena e é branco, faz parte da cultura e da tradição; é falante da língua e, portanto, possui identidade Terena. Assim, as vozes trazidas pelo sujeito, por meio dos pronomes possessivos na primeira pessoa do plural, revelam a heterogeneidade constitutiva do sujeito: a cultura Terena (festas, costumes), a língua Terena como constituidora da autenticidade indígena e, por último, as vozes da tradição (a própria língua, a divisão social interna, os rituais). Corrobora-se, aqui, a teoria de Authier-Revuz (1990): o discurso é produto do interdiscurso, isto é, o centro de um exterior constitutivo, em que há o sujeito (EU) e o Outro (psicanalítico) ${ }^{7}$, o eu fragmentado, mas que recebe as influências do Outro.

Authier-Révuz (1990, p. 33) entende que a heterogeneidade constitutiva é um "ato individual de apropriação que introduz aquele que fala em sua fala". Ao inserir-se no Outro e ao trazê-lo, por meio das marcas discursivas "nosso", "nossos", o sujeito busca mostrar (ilusoriamente) que a língua deixa-o forte, com identidade Terena fixa e definida ("nossa língua"). Podemos afirmar, portanto, que as estratégias discursivas utilizadas por CT 2

\footnotetext{
7 Teoria lacaniana que concebe o Outro do discurso como constituído tanto pelo interdiscurso, como pelo inconsciente, afirmando um enunciador externo ao seu discurso. (AUTHIER-RÉVUZ, 1990, p. 32).
} 
articulam-se na ordem do poder, como pertencimento de um povo, de uma etnia. A partir de discursos nessa ideologia de poder/pertencimento é que o sujeito estreita a necessidade de valorização da língua e da cultura, pois a representação da língua como mecanismo de representação de vitimização é latente quando a proficiência da língua Terena não está em curso, dentro e fora da etnia.

Esse desejo de indianidade que, ao mesmo tempo, denuncia um dos seus, presente no discurso de CT 2, é abordado por Bauman (2005, p. 55) como característica das identidades modernas, como traço e como "algo que os indivíduos tinham de desempenhar [...] provar pelos atos, 'pela vida inteira", como se tivessem que prestar contas por pertencer a uma classe - caso contrário, haveria uma conspiração para uma desclassificação. É no advento da pós-modernidade que CT 2 denuncia uma situação de não cumprimento do "provar pelos atos", que o leva a representar a língua (e com ela a indianidade Terena) como elemento de vitimização. Há perdas de poder interno e perante a sociedade; este último, pelo espelhamento dos valores de verdade que são refletidos por aquela. (GUERRA; PORTO, 2013).

A progressão referencial, introduzida inicialmente por meio do enunciado "A aldeia de Bananal onde moram nossos patrícios" e que instaura a ideia de origem, é retomada por meio do pronome "nossos": trata-se de um "nosso- inclusivo", que seria a junção de $m e u+$ seu. Ao usar o possessivo "nossos", o enunciador inclui-se em um todo abrangente, em que o pronome remete ao incluído e o substantivo "patrícios" designa "o todo includente", a coletividade que o recebe e que o legitima como o porta-voz do movimento. Além disso, traz para o discurso todas as lideranças presentes no acontecimento discursivo e que mantêm entre si uma mesma correlação de subjetividade. Por considerarmos que o lugar a partir do qual o sujeito enuncia é constitutivo dos sentidos de seu dizer, enfatizamos que o enunciador da cartilha Terena fala a partir da posição que ocupa na instituição como professor/ representante desse movimento didático e pedagógico que visa à valorização.

Vale dizer que as aldeias Bananal e Cachoeirinha são consideradas como antigas e tradicionais dos povos, e seus moradores usam o português somente na presença do branco, o que sugere certo "poder" destas sobre as demais. Bananal, por exemplo, fica no centro de um complexo e é considerada a mais importante pelo número de indivíduos que falam a língua Terena em todas as situações cotidianas, num total de sete aldeias. Essa condição de poder atribuída à língua Terena advém da posição sustentada pela própria instituição que recebeu o presidente do Brasil: "Havia muitas pessoas querendo ver o nosso Presidente".

No fio discursivo, verificamos que o advérbio de inclusão "também”, que incorpora outros elementos à enunciação (NEVES, 2000, p. 240), vem articular a ideia de inclusão a partir do enunciado "Também veio um presidente da FUNAI". Ou seja, além do presidente do Brasil, havia, visitando a aldeia Terena, outra autoridade, particularmente ligada às questões indígenas. $\mathrm{O}$ discurso do CT 2 , portanto, faz-se político à medida que se torna o lugar de concorrência pelo poder, pelo direito de falar em nome de uma parcela de indivíduos, de uma coletividade: faz que esse grupo adquira certa visibilidade perante a sociedade e o campo político. O advérbio "também”, no final de CT 2, aponta para práticas políticas da região: índio gosta de carne, razão pela qual nas campanhas eleitorais há muitos churrascos nas aldeias. $\mathrm{O}$ atual prefeito de Aquidauana, embora sob denúncias de compra de votos, prometeu até a instalação de um açougue na região das aldeias, onde a carne seria comercializada a $\mathrm{R} \$ 1,00$ (um real) o quilo.

Tais efeitos de sentido nesse discurso analisado remetem aos estudos de Mignolo (2003, p. 35), quando propõe, como saída para a reflexão crítica feita das margens, "a descolonização e a transformação da rigidez de fronteiras epistêmicas e territoriais estabelecidas e controladas pela colonialidade do poder, durante o processo de construção do sistema colonial/moderno". Ambas as passagens, enquanto prática crítica pós-subalterna, sinalizam que o processo transculturador, demandado pela cultura fronteiriça e suas histórias 
locais, híbridas, situadas entre lá e cá, cria um entre-lugar (SANTIAGO, 2000) cultural povoado de sensibilidades biográficas de afetos e de memórias subalternas que transitam, sem culpa, entre o local e o global. Assim, resta-nos, amparados pelo pensamento de Bhabha (1998, p. 27), propor um trabalho crítico que descolonize as fronteiras epistêmicas impostas pelo sistema colonial moderno.

\section{O MATERIAL DIDÁTICO E A CONSTRUÇÃO DE “NOVAS IDENTIDADES”}

[A Escola] funciona como repressora toda uma micropenalidade do tempo (atrasos, ausências, interrupções das tarefas), da atividade (desatenção, negligência, falta de zelo), da maneira de ser (grosseira, desobediência), dos discursos (tagarelice, insolência), do corpo (atitudes "incorretas", gestos não conformes, sujeira), da sexualidade (imodéstia, indecência). (FOUCAULT, 2009, p. 194)

Diante do exposto, verificamos, nos recortes analisados, que o discurso da cartilha Terena para os povos indígenas ainda está perpassado pela discriminação por parte da sociedade do branco, revelando que o espaço escolar não diminui o estranhamento do branco em relação aos habitantes indígenas, com sua cultura e identidade históricas. Imprime-se aqui um modelo social, e o que não se enquadra nesses padrões é considerado marginal, transgressor e inferior. Os enunciados denunciam a dificuldade que a sociedade tem em lidar com o diferente, como em "vieram mulheres da cidade para fazer almoço para o presidente". O efeito de sentido aqui é o de que as mulheres indígenas não poderiam cozinhar para o presidente (não estariam capacitadas para tal tarefa), ou que o presidente não poderia tolerar a alimentação oferecida pela comunidade indígena.

Nesse contexto discursivo de poder social, histórico, globalizado, comprovamos a hipótese de que o discurso da cartilha, na condição de material didático, contribui para as relações de saber/poder dos povos indígenas, impondo-lhes "novas identidades", como branco, forçando-os a uma construção identitária considerada fluida e múltipla, em que ao indígena Terena ainda é atribuída a representação de incapaz e de submisso às regras sociais do branco.

Isso é passível de ser verificado na tentativa de homogeneização da cultura: dificilmente as cartilhas falam sobre as minorias ou sobre aqueles que passam por situações de preconceito por serem negros, homossexuais, pobres, portadores de necessidades especiais, por não se enquadrarem num padrão de beleza, comportamento e cultura mobilizado pela mídia, de modo geral. Suas discursividades camuflam a realidade hostil da qual os povos indígenas fazem parte, e suas vidas tornam-se (in)descritíveis à medida que são atravessadas pelos mecanismos de um poder hegemônico e político que dissemina a exclusão, via discurso da inclusão.

A escritura contida na cartilha, de uso difundido nas escolas, é uma história fortemente posicionada de uma ótica europeia, branca e cristã, assim como todos os fatos e acontecimentos que marcaram o passar do tempo em nosso país, desde o ano de 1500 até hoje, narrados por um olhar nitidamente europeu. O estudante acaba sendo "convidado" a apreender noções unilaterais de determinados feitos, que lhe limitam o exercício da crítica e o fazem enveredar por um caminho tendente ao preconceito, no que tange à diversidade cultural.

É problemática a postura adotada pelos manuais que encerram uma ótica genérica referente aos índios, já que não lhes prestam devida individualização ou vinculação tribal, determinante de sua origem. Muitas vezes, de forma parcial, os índios só são apontados como "cordiais", ou não selvagens, quando aliados dos brancos, e, ainda, como "inimigos", 
quando opositores do "progresso" europeu pretendido. O indígena será "selvagem e bravo" para ressaltar a coragem dos primeiros exploradores; preguiçoso e indolente no contexto da escravidão; e corajoso e inocente para a construção romantizada de uma identidade nacional mestiça. Perguntamos: As culturas ameríndias serão marcadas pela ausência: falta da escrita, falta de governo, falta de tecnologia para lidar com metais (Kadiwéu), falta de agricultura (Terena, Kinikinau), entre outras "faltas" que justificariam suas participações simplificadas e pontuais em nossa história?

Em meio a todos os desconfortos vivenciados pelo indígena Terena na luta pela identidade, origem, mitos e língua, é em suas tradições, em sua cultura que ele encontra certo conforto em "um sonho de pertencimento", como afirma Bauman (2005, p. 20).

Diante dessas reflexões, fica a ideia de que a zona de fronteira aqui em debate, talvez por sua condição mesma de liminaridade (diaspórica e subalterna), encontra-se aberta para uma prática de hospitalidade que é, ao mesmo tempo, hospitaleira e hostil. E, por conseguinte, por estar historicamente aberta para todos os convidados (hospitalidade incondicional) e visitantes (hospitalidade condicional) desencadeia um processo de transculturação infinita.

\section{REFERÊNCIAS}

AUTHIER-RÉVUZ, Jacqueline. Heterogeneidade(s) Enunciativa(s). Cadernos de Estudos Linguísticos, n.19.Tradução de Celeste M. Cruz e João Wanderley Geraldi. Campinas, IEL/Unicamp, 1990, p. 25-42.

BARTHES, Roland. S/Z. Traduçãode Maria de S. Cruz e Ana M. Leite. Lisboa: 70, 1980.

BAUMAN, Zygmund. Identidade: entrevista a Benedetto Vecchi. Tradução Carlos Alberto Medeiros. Rio de Janeiro: Jorge Zahar, 2005.

BHABHA, Homi. O local da cultura. Tradução de Myriam Ávila, Eliana L. de L. Reis, Gláucia R. Gonçalves. Belo Horizonte: Editora UFMG, 1998.

CARMAGNANI, Ana M. G. A concepção de professor e de aluno no livro didático e o ensino de redação em LM e LE. In: CORACINI, Maria J. R. F. Interpretação, autoria e legitimação do livro didático: Língua Materna e Língua Estrangeira. Campinas: Pontes, 1999, p. 127-133.

CORACINI, Maria J.R.F. (Org.) Interpretação, autoria e legitimação do livro didático: Língua Materna e Língua Estrangeira. Campinas: Pontes, 1995.

A celebração do outro: arquivo, memória e identidade. Campinas: Mercado de Letras, 2007.

História de vida e pobreza: por uma (intro)dução. In: CORACINI, M. J. R. F. Identidades silenciadas e (in)visíveis: entre a inclusão e a exclusão. Campinas: Pontes, 2011, p.17-28.

CUNHA, Manuela C. Introdução a uma história indígena. In: . (org.). História dos índios no Brasil. 2. ed. São Paulo: Companhia das Letras, 1992, p. 9-24.

DERRIDA, Jacques. A escritura e a diferença. Tradução de Maria B. M. Nizza da Silva. São Paulo: Perspectiva, 1995. 
O monolinguismo do outro. Ou a prótese de origem. Tradução de Fernanda Bernardo. Porto: Campo das Letras, 2001.

Anne Dufourmantelle convida Jacques Derrida a falar da hospitalidade. Tradução de Antonio Romane e Paulo Ottoni. São Paulo: Escuta, 2003. 2005.

.A farmácia de Platão. 3. ed. Tradução de Rogério da Costa. São Paulo: Iluminuras,

ECKERT-HOFF, Beatriz N. Escritura de si e identidade: o sujeito professor em ação. Campinas, São Paulo: Mercado das Letras, 2008. 152 p.

FOUCAULT, Michel. Method. In The history of sexuality. V1, Vintage, 1990. p. 92-102.

Theatrum Philosophicum. Critique, n 282, 1970, p. 885-908. Trad. bras. Ditos e Escritos II: Arqueologia das Ciências e História dos Sistemas de Pensamento. Tradução de E. Monteiro. Rio de Janeiro: Forense Universitária, 2005.

Vigiar e punir: nascimento da prisão. 37 ed. Tradução de Raquel Ramalhete. Petrópolis: Vozes, 2009.

.Microfísica do poder. Tradução de Roberto Machado. Rio de Janeiro: Graal, 2010.

FREIRE, J. R. B. A imagem do índio e o mito da escola. In: MARFAN, M. A. (Org.). Congresso Brasileiro de Qualidade na Educação - Formação de professores: educação escolar indígena. Brasília: MEC, 2002, p. 93-99.

GOBBI, Izabel. A temática indígena e a diversidade cultural nos livros didáticos de História: uma análise dos livros recomendados pelo Programa Nacional do Livro Didático. São Carlos. Dissertação- Mestrado. Programa de Pós-Graduação em Ciências Sociais, Universidade Federal de São Calos. 2006.

GREGOLIN, Maria do R. Foucault e Pêcheux na análise do discurso: diálogos \& duelos. 2. ed. São Carlos: Claraluz, 2006. 210 p.

GUERRA, Vânia M. L. O indígena de Mato Grosso do Sul: práticas identitárias e culturais. São Carlos: Pedro e João, 2010, 160 p.

Um estudo discursivo de textos produzidos por alunos indígenas: identidade e exclusão. In: GUERRA, Vânia M. L.; ENEDINO, Wagner C.; NOLASCO, Edgar C. (Orgs). Estudos de linguagens: diversidade e ensino. São Carlos: Pedro e João, 2012, p. 31-45.

GUERRA, Vania M. L.; PORTO, Alessandra M. Subjetividade e discurso: a representação da língua (indígena e portuguesa) para professores Terena. Revista Rua, Laboratório de Estudos Urbanos (Labeurb/UNICAMP) Campinas, n.19, jun/2013. 
LIMBERTI, Rita de C. P. Discurso indígena: aculturação e polifonia. Dourados: UFGD, 2009.

MIGNOLO, Walter. Histórias locais/Projetos globais: colonialidade, saberes subalternos e pensamento liminar. Tradução de Solange R. de Oliveira. Belo Horizonte: Editora UFMG, 2003.

MOREIRA, Vânia M. L. Os índios e a historiografia. Dimensões, Espírito Santo, v. 13, p. 268-278, jul/dez, 2000.

LACAN, Jacques. Situação da Psicanálise e formação do analista em 1956. In:

Escritos. Tradução de Inês Oseki-Depré. Rio de Janeiro: Zahar, 1998.

NOLASCO, Edgar, C. Bugres subalternus. Cadernos de Estudos Culturais, v. 1, n.1, Campo Grande: Editora UFMS, 2009, p. 9-16.

NOVAES, Adauto. A outra margem do ocidente. São Paulo: Companhia das Letras, 1999.

OLIVEIRA, Roberto C. Do índio ao bugre: o processo de assimilação dos Terêna. 2. ed. Rio de Janeiro: Alves, 1976.

ORLANDI, Eni P. As formas do silêncio. No movimento dos sentidos. 6. ed, Campinas: Editora Unicamp, 2007.

$100 \mathrm{p}$.

Análise de discurso: princípios e procedimentos. 8. ed, Campinas: Pontes, 2009,

PÊCHEUX, Michel. [1975] Semântica e discurso: uma crítica à afirmação do óbvio. Tradução de Eni P. Orlandi. Campinas: Editora Unicamp, 1988.

RANCIÈRE, Jacques. O desentendimento.Tradução de Ângela Leite Lopes.São Paulo: 34, 1996.

SANTIAGO, Silviano. O entre-lugar do discurso latino-americano. In: SANTIAGO, Silviano. Uma literatura nos trópicos. 2. ed, Rio de Janeiro: Rocco, 2000, p. 09-26.

SPIVAK, Gayatri C. Pode o subalterno falar? Tradução de Sandra Regina Goulart Almeida; Marcos Pereira Feitosa; André Pereira. Belo Horizonte: Editora UFMG, 2003.

Recebido em 30/04/2014

Aprovado em 04/11/2014 